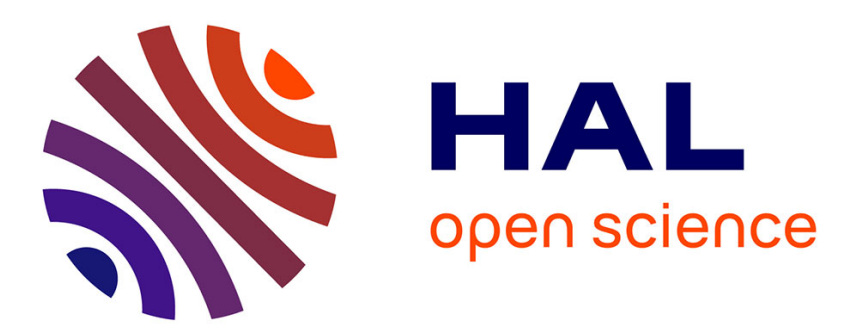

\title{
Experimental Flash Pyrolysis of High Density PolyEthylene under Hybrid Propulsion Conditions
}

Nicolas Gascoin, Guillaume Fau, Philippe Gillard, Alexandre Mangeot

\section{To cite this version:}

Nicolas Gascoin, Guillaume Fau, Philippe Gillard, Alexandre Mangeot. Experimental Flash Pyrolysis of High Density PolyEthylene under Hybrid Propulsion Conditions. Journal of Analytical and Applied Pyrolysis, 2013, pp.1-11. 10.1016/j.jaap.2013.02.014 . hal-00796085

\section{HAL Id: hal-00796085 \\ https://hal.science/hal-00796085}

Submitted on 1 Mar 2013

HAL is a multi-disciplinary open access archive for the deposit and dissemination of scientific research documents, whether they are published or not. The documents may come from teaching and research institutions in France or abroad, or from public or private research centers.
L'archive ouverte pluridisciplinaire HAL, est destinée au dépôt et à la diffusion de documents scientifiques de niveau recherche, publiés ou non, émanant des établissements d'enseignement et de recherche français ou étrangers, des laboratoires publics ou privés. 


\section{PolyEthylene under Hybrid Propulsion Conditions}

\author{
Nicolas Gascoin $^{1 *}$, Guillaume Fau ${ }^{1}$, Philippe Gillard ${ }^{1}$, Alexandre Mangeot ${ }^{1,2}$ \\ ${ }^{1}$ University of Orléans, 63 avenue de Lattre de Tassigny, 18020 Bourges, France \\ ${ }^{2}$ Centre National d'Etudes Spatiales, Rond Point de l'Espace, 91023 Evry Cedex, France
}

The inert and oxidative flash pyrolysis of High Density Poly-Ethylene (HDPE) is studied up to $20000 \mathrm{~K} . \mathrm{s}^{-1}$, under pressure up to $3.0 \mathrm{MPa}$ and at temperature ranging from $1000 \mathrm{~K}$ to $1500 \mathrm{~K}$. These conditions are considered to represent those waited onboard a hybrid rocket engine using HDPE as solid fuel. Recycling applications may also find some interest. The pyrolysis products are quantified by Gas Chromatograph, Flame Ionisation Detector and Mass Spectrometer to determine the effects of each physical parameter on the HDPE decomposition. The classical products distribution diene-alkene-alkane for each carbon atoms number is shown to be modified at such high temperature because of the pyrolysis of primary products. The pressure effect, which is generally neglected in HDPE pyrolysis studies found in open literature, is proved to be a major factor (up to one order of magnitude on the ethylene mass fraction). The heating rate presents noticeable consequences on the pyrolysis products distribution with a larger formation of light species while heavier ones are favoured under oxidative pyrolysis conditions. The experimental data should serve in the future to improve the accuracy of kinetic mechanisms for later use in numerical computing and to serve in related combustion studies for propulsive applications.

\footnotetext{
* Corresponding author: nicolas.gascoin@univ-orleans.fr, Tenure Professor, Tel.: +33 248238 473; Fax: +33 248 238 471, 63 avenue de Lattre de Tassigny, 18020 Bourges Cedex FRANCE
} 
Keywords: Polyethylene; flash pyrolysis; heating rate and pressure effects; design of experiments; hybrid propulsion.

\section{Introduction}

High Density Polyethylène (HDPE) is presently of high interest in numerous civil applications of daily life, which explains the number of works related to its recycling [1]-[5]. In addition, this polymeric material may be of interest for hybrid rocket propulsion [6] despite this solid fuel presents one major drawback. Indeed, its low regression rate makes the combustible generation to be too low to provide interesting thrust [7]. Summarising the fundamentals of hybrid engine, it can be recap that the solid fuel constitutes the combustion chamber in which the oxidiser is injected. For this reason, the combustion generates the heat flux which serves to pyrolyse the fuel and to produce the gaseous combustible fuel [7]. A complex phenomenology occurs at the solid surface with regression, diffusion flame and possible melting layer with spray generation when using liquefying fuel [7].

It is hoped to cope the weak point of the low HDPE regression rate by the transient production of light compounds with low auto-ignition delay. Indeed, it was found in previous work that the nature of the chemical species produced by the fuel pyrolysis changes depending on the pyrolysis conditions [8]. Hence, it may be possible to produce chemical compounds with low auto-ignition delay which would burn close to the solid regression surface[9]. This would reinforce the heat transfer and thus the fuel pyrolysis. As a consequence, this would increase the regression rate. Thus, it is required to conduct an adequate experimental study to determine in which conditions, such species would be favoured.

Firstly, low heating rates are generally encountered in open experimental literature since Thermogravimetric analysis or other conventional experimental devices are used to ensure the thermal degradation [4],[10],[11]. For this reason, a flash pyrolysis system should be preferred. Secondly, the operating pressures are often far from those encountered in real hybrid rocket engine conditions (over $3 \mathrm{MPa}$ ) but merely the atmospheric one [12]. Last, the maximum temperature found in existing pyrolysis works is reported by Elordi et al. (988 K) [13] while the one expected in hybrid combustor easily overpasses $1000 \mathrm{~K}$ [14]. Some works considering combustion of HDPE also consider higher temperature but the two chemical regimes (pyrolysis/combustion) are not easily isolated [7], [9], [15]. Consequently, a clear lack of data is found for the specific conditions to be found in hybrid engines. This 
justifies the present work which should provide data for a later use in numerical computations and kinetic mechanisms conception.

Numerically, a limited number of detailed kinetic schemes is found for HDPE [12], [16]. Mastral et al. reported the lack of appropriate pyrolysis data for HDPE [10]. Most of the chemical mechanisms lump the gas species into a single one and similarly for the solid and liquid phases [2], [3], [17]-[19]. Some work even consider a single degradation step for the polyethylene [20], [21]. This may be of interest for recycling purpose to find the optimum valuing conditions but this is not appropriate for aerospace applications. A gas species can be methane or acetylene, which is absolutely different from a combustion point of view (several orders of magnitude on the auto-ignition delay) [22]. Thus, the identification of each compound requires a detailed kinetic mechanism. A reduction work has conducted to such a scheme with 1713 reactions and 472 species instead of 7541 reactions and 1014 species [23]. This kinetic scheme is intended to be used in Computational Fluid Dynamics code [14] but it requires being validated first under operating conditions in agreement with those expected on the hybrid rocket engine. In this perspective, the experimental data to be obtained in the present work should be determining.

Finally, from a fundamental point of view, additional data related to the HDPE pyrolysis could be fruitful to analyse the main chemical pathway of reactions. The main ones are well-known and have been described by Wampler [24]. Initiation reactions generate by random scission the primary radicals which then form alkenes by $\beta$ scission and alkanes by $\mathrm{H}$-abstraction when reacting with the polymeric molecule. Similar reactions conduct to diene formation. The typical products distribution profile shows triple peaks for each carbon atom number. Each of the primary products is then pyrolysed depending on the test conditions. The relative concentration of each chemical group then varies while it is initially linearly linked with the carbon atom number [25]. Further details on HDPE pyrolysis and associated kinetic schemes can be found in Ref. [23].

This work aims at furnishing reliable pyrolysis data for HDPE under unexplored conditions, which are those encountered onboard a hybrid engine. For this purpose, it relies on flash-pyrolysis experiments; coupled to additional ThermoGravimetry analysis to estimate the pyrolysis rate as a function of the temperature. The effects of the physical parameters on the HDPE pyrolysis and on the products formation are investigated through a design of the experiment. A deep quantification work is carried out on the product formation. 


\section{Materials and methods}

The HDPE is sourced from Politek (PE1000). On the basis of the data furnished by the manufacturer, the HDPE presents the following main characteristics: white colour, density of $940 \mathrm{~kg} \cdot \mathrm{m}^{-3}$ and thermal conductivity of $0.38 \mathrm{~W} \cdot \mathrm{m}^{-1} \cdot \mathrm{K}^{-1}$. In addition, a large characterisation work has been achieved prior to the present study in order to have all the properties which would be suitable for engineering and scientific uses of this HDPE. These data are given in section 3.1.

\subsection{Pyrolysis devices}

A high pressure flash pyrolysis system (CDS, $5200 \mathrm{HP}$ ) has been connected to a Gas Chromatograph (Varian, 3800 with Varian MS Workstation 6.9 software) equipped with a Flame Ionisation Detector in parallel to a Mass Spectrometer (Varian, Saturn 4000 with ion trap). A Platinum coil is electrically heated to heat the sample placed within a quartz tube. The flash pyrolyser is used in trap-mode, which enables accumulating the pyrolysis products on a triple-bed trap (CDS, 90mg-60:80-Tenax-TA ${ }^{\mathrm{TM}} /$ Carboxen 1000/Carbosieve $\left.{ }^{\mathrm{TM}} \mathrm{SIII}\right)$ before flushing the species to the GC through the split/splitless injector (Varian, 1177, internal volume: $0.95 \mathrm{ml}$ ). Helium is used as carrier gas with a constant flow rate of $30 \mathrm{ml} \cdot \mathrm{min}^{-1}$ (independent from the operating conditions). This corresponds to a residence time for volatiles around $1 \mathrm{~s}$ in the system. Fused silica (Agilent, $0.32 \mathrm{~mm}, 10 \mathrm{~m}$ ) with a split ratio $1 / 10$ is used to equilibrate the flows between the two detectors. A GS-CARBONPLOT column (Agilent, $0.32 \mathrm{~mm}, 30 \mathrm{~m}$, 3.0) is connected on the FID to separate the light compounds (C1-C8). A VF-5ht column (Agilent, $0.32 \mathrm{~mm}, 30 \mathrm{~m}$, $0.10)$ is placed on the MS line to separate the heavy species (C8-C26). A quantification work (detailed in next section) allows determining the quantity of each pyrolysis product.

Apart the above process-analysis coupled device, a ThermoGravimetry apparatus has been employed (SETARAM, Setsys 16/18). It enables weighting solid samples during thermal degradation up to $2000 \mathrm{~K}$. Argon has been used has carrier gas and alumina crucible served to depose the HDPE sample. Initial and final weights of samples were controlled by a mass balance to confirm the TG data. The pyrolysis rate (consumed mass of sample divided by the initial one) is expressed so as to the regression rate (consumed mass of HDPE over the time of consumption). The regression rate is converted in $\mathrm{mm} \cdot \mathrm{s}^{-1}$ instead of $\mathrm{mg} \cdot \mathrm{s}^{-1}$ as measured by the TG by assuming cubic samples.

\subsection{Test conditions and Design of experiments}


A two-level design of experiments [26] is proposed to determine the effects and their quantitative importance on the HDPE pyrolysis with the flash pyrolysis device (Table 1). An additional temperature has been added (1250 K) between the two levels $(1000 \mathrm{~K}$ and $1500 \mathrm{~K})$ to provide temperature dependence profile of the species formation/consumption. The programming of the flash pyrolysis consists in a heating with a slope equal to the heating rate to reach the final temperature. After $15 \mathrm{~s}$ of thermal plateau at this maximum temperature (during which the pyrolysis species are trapped thanks to the flow of reactant gas), the trap is desorbed during 2 min with He. The transfer line to the GC is heated to $623 \mathrm{~K}$ (same desorption temperature as the trap).

\section{Table 1 should be placed here}

A calibration of the $\mathrm{GC}$ detectors has been achieved prior to the experiments to identify and quantify the products. For this purpose, standards have been injected with different successive dilution factors. To limit the quantification work, 44 species ranging from $\mathrm{C} 1$ to $\mathrm{C} 26$ are analysed (including the main possible chemical groups: diene, alkene, alkane). These species are the major one observed during the experiments. Tens to hundreds other species are found under negligible quantities $(<50 \mathrm{ppm})$. The MS parameters are the classical ones [28] with a scan from 15 to $350 \mathrm{~m} / \mathrm{z}$ ratio. The $\mathrm{GC}$ thermal programming is isothermal at $303 \mathrm{~K}$ during 3 min before a slope at $20 \mathrm{~K} \cdot \mathrm{min}^{-1}$ up to $623 \mathrm{~K}$ and then a thermal plateau during about $30 \mathrm{~min}$.

Finally, the TG programming includes a thermal plateau at $303 \mathrm{~K}$ during $30 \mathrm{~min}$, then a heating with a slope of $20 \mathrm{~K} \cdot \mathrm{min}^{-1}$ and finally a last thermal plateau of $30 \mathrm{~min}$ at the maximum desired setup temperature $(633 \mathrm{~K}$ to $773 \mathrm{~K}$ by step of $20 \mathrm{~K}$ ). Two reactant gases (inert with Argon or oxidative with Air) are used to qualify the atmosphere effect.

\section{Results and Discussion}

\subsection{Characterisation of the HDPE sample and tests repeatability}

A preliminary characterisation of the HDPE has been done despite it is not the aim of the present work. A coupled analysis has been achieved by Fourier Transform Infrared spectrometer (Diffuse reflection) and Electron Dispersive Scanning (with Scanning Electronic Microscope). Negligible presence of phenol additives is suspected. Differential Scanning Calorimeter (DSC) analysis confirmed a melting point around $138{ }^{\circ} \mathrm{C}$, a fusion enthalpy of $205 \mathrm{~J}^{-1} \pm 31{\mathrm{~J} . g^{-1}}^{-1}$ and the crystallinity of the polymer was estimated to reach $72 \% \pm 11 \%$. To get this last value, the 
method consisting in dividing the fusion enthalpy by the HDPE theoretical one $\left(285 \mathrm{~J}_{\mathrm{g}}{ }^{-1}\right)$ was used. The main results are given in Ref. [27].

Concerning the experiments, the test repeatability has been verified by three to four successive experiments in the same conditions with both apparatus (TG and flash pyrolyser). Regarding the TG results (Figure 1a), the final conversion rate is reproducible but the larger the sample, the slower the conversion. Here, mass from $0.85 \mathrm{mg}$ to almost $6 \mathrm{mg}$ have been tested. This observation is well-known and it is linked to the thermal heterogeneity when the sample is too large. Concerning the flash pyrolysis system (Figure 1b), a large repeatability study has been achieved systematically concerning the apparatus and concerning the size of the samples. Because of the numerous species and the difficulty to properly separate each peaks of the chromatogram and of the mass spectrogram, a disagreement up to $20 \%$ can be found for some species while it is generally less than $5 \%$. For this reason, it has been preferred to determine the average value after three tests for each condition. This method is the one used in the present study and the results given later will be those of the mean value. The reason of the discrepancies has been investigated. It is first due to the ability of the authors to produce constant samples mass and shape. Regarding the size of the solid sample, it should be limited to few hundreds of microns, which is difficult experimentally. Thus, a large error could be observed without rigorous sample preparation method. Consequently, the samples were prepared by cutting them directly and manually from an initial homogeneous solid block of HDPE. Several tens of samples were prepared and then observed by microscope to quantify their size. Those with a similar size around $400 \mu \mathrm{m}$ were selected. The final dispersion is $\pm 20 \mu \mathrm{m}$. The second main reason of the discrepancies is due to the fact that the pyrolysis products are trapped after being generated by the pyrolysis. Hydrogen is lost through this step. The products are then released by thermo-desorption to the GC/MS analytical device (at $350^{\circ} \mathrm{C}$ ). The heavier species thus may remain in the trap. This impacts the mass balance which cannot be verified during the experiments.

\section{Figure 1 should be placed here}

In addition, an extended numerical work has been conducted with analytical laws and multiphysics code (Fluent, Comsol) to determine if the sample temperature within the flash pyrolysis probe dynamically follows the setup temperature, particularly for the high heating rates. It was notably found that even at $20000 \mathrm{~K} . \mathrm{s}^{-1}$, the sample temperature reaches the one of the setup after $1 \mathrm{~s}$.

\subsection{First pyrolysis data}


Inert and oxidative TG experiments from $633 \mathrm{~K}$ to $773 \mathrm{~K}$ have been achieved (Table 2). The pyrolysis rate reaches $100 \%$ for approximately the same temperature whatever the atmosphere. Nevertheless, the dynamics of the pyrolysis changes between the inert and the oxidative cases. Considering the pyrolysis rate enables estimating the amount of combustible gaseous species which can be produced during the use of hybrid rocket engine depending on the test conditions. The regression rate (either in $\mathrm{mm} \cdot \mathrm{s}^{-1}$ or in $\mathrm{mg} \cdot \mathrm{s}^{-1}$ ), in addition to the pyrolysis rate, gives additional information on the dynamic of the pyrolysis process. The regression rate in $\mathrm{mg} \cdot \mathrm{s}^{-1}$ is given directly by $\mathrm{TG}$ results while expressing it in $\mathrm{mm} \cdot \mathrm{s}^{-1}$ is of interest for technologic use in hybrid rocket engine because this allows estimating the combustion port diameter for example. This rate (in $\mathrm{mm} \cdot \mathrm{s}^{-1}$ for example) is higher for the oxidative pyrolysis and it increases much faster in this condition than in inert condition (Table 2). The ratio between these two tests ranges from 1.6 at $633 \mathrm{~K}$ to 6.7 at $773 \mathrm{~K}$ (in favour to the oxidative case). The temperature of self ignition for HDPE ranges in the literature from $603 \mathrm{~K}$ to $683 \mathrm{~K}$ [29]. Thus, it could be assumed that a slow combustion, or oxidation process, occurs during the pyrolysis which enhances the heat transfer and promotes the HDPE consumption. Consequently, this confirms the need to consider the atmosphere in the design of experiments, as proposed in Table 1, to dissociate the thermal effect and the chemical one of the heterogeneous reactions. The oxidation reactions should be clearly seen in DSC through an exothermic peak. It can be noticed that the TG curves under oxidative atmosphere present different slopes with inflexion point around $673 \mathrm{~K}(3100 \mathrm{~s})$, which tends to confirm the oxidation process and the existence of a HDPE oxidation induction delay (Figure 2).

\section{Table 2 should be placed here}

Figure 2 should be placed here

The regression rate measured with the TG (Figure 4a) clearly differs between inert and oxidative cases as mentioned above. Using a classical Arrhenius law, the pre-exponential factor is found to be equal to $7.52 .10^{6} \mathrm{~s}$ (for $10^{8}$ in Ref. [30]) and the activation energy is $124 \mathrm{~kJ}^{\mathrm{mol}}{ }^{-1}$ (for $130 \mathrm{~kJ} \cdot \mathrm{mol}^{-1}$ in Ref [30]). In addition (Figure 4b), the estimated regression rate in $\mathrm{mm} \cdot \mathrm{s}^{-1}$ is about 20 times less than the one generally observed in real hybrid rocket conditions [7], that is to say $0.2 \mathrm{~mm} \cdot \mathrm{s}^{-1}$. This is attributed to the heating rate and to the temperature of the sample. Indeed, the heating rate in hybrid combustor is estimated around $10^{5} \mathrm{~K} . \mathrm{s}^{-1}$, much higher than $20 \mathrm{~K} . \mathrm{min}^{-1}$ in the TG. As a consequence, reaching $1000 \mathrm{~K}$-at least- would demand $35 \mathrm{~min}$ with TG device. This time is far too important to be representative of real conditions and this explains why TG tests have been achieved up to $773 \mathrm{~K}$ maximum. Furthermore, the fact that the regression rate is higher for the oxidative atmosphere (which takes benefit of additional heat release due to oxidation reaction) demonstrates that a higher heating rate (or heat release rate) 
promotes the regression rate. For this reason, additional experiments in flash pyrolysis system (up to $2.10^{4} \mathrm{~K} . \mathrm{s}^{-1}$ ) are proposed in the following section.

\section{Figure 3 should be placed here}

\subsection{Parametric study of flash pyrolysis}

In conformity with the parameters and their respective levels given in the design of experiment (Table 1), the composition of each corresponding pyrolysis mixture is given in Table 3 (each data is the mean value determined after three replicate tests). An example of some mass spectrograms acquired during the analysis of the pyrolysis mixtures is furnished by Figure 5. The differences between the different test conditions are significant (Table 3) since they are higher the reproducibility which has been tested. The quantities of dienes, alkenes and alkanes are also given to quantify their relative importance at each test condition. Methane and acetylene are found in trace quantity and hydrogen is not quantified for trapping reason. As mentioned in introduction, the classical dienealkene-alkane triple peak is observed for some carbon atoms number (for example C9 to C13). For some others, for example C8 and C15 and over, it was not possible to isolate the three chemical groups due to co-elution. As a consequence, the three species are lumped into the alkene molecule for quantification purpose. The peak is referred to $\mathrm{Cx}$ to clearly mention this point. Since the alkenes are the major compounds, this decreases the error inherited from this correction. It can be noted that the ethylene content decreases when the temperature increases. This is related to its pyrolysis which is favoured at lower pressure.

\section{Table 3 should be placed here}

Figure 4 should be placed here

On the basis of these results, the products formation is plotted versus the temperature to identify the separate effects of the atmosphere (Figure 6), of the pressure (Figure 7) and of the heating rate (Figure 8). Despite only three temperatures were tested, the variations are greater than the uncertainties (marked with error bars) and the discussion of the results justify considering them. The alkene formation is only slightly impacted by the temperature (in the range 60 mol.\%-70 mol.\%) and even less by the atmosphere (Figure 6). A balance is observed between alkanes and dienes depending on the tested temperature. The alkane formation decrease is compensated by the increase of the diene production. Considering the atmosphere effect, it mostly impacts the dienes and alkanes, with a minimum effect around $1250 \mathrm{~K}$. This point is complex to explain since the chemistry of oxidative pyrolysis implies heterogeneous reactions between the HDPE and the air. The dienes/alkenes/alkanes present molecular weight from 
low to high value. Some of them are produced and other consumed depending on the temperature and atmosphere. Thus, additional analysis will be provided in next section thanks to the design of experiments.

\section{Figure 5 should be placed here}

At higher pressure $(3 \mathrm{MPa})$, the temperature effect is decreased since the dienes, alkenes and alkanes formation fluctuates in a lower extent between $1000 \mathrm{~K}$ and $1500 \mathrm{~K}$ (Figure 7). The bimolecular reactions do play a role at high pressure -due to the concentration effect of species-. At $3 \mathrm{MPa}$, the dienes quantity linearly increases with the temperature while the one of alkanes decreases. Similarly, decreasing the heating rate from $2.10^{4} \mathrm{~K} \cdot \mathrm{s}^{-1}$ to $10^{2} \mathrm{~K} . \mathrm{s}^{-1}$ results in a linear increase of the dienes quantity (Figure 8). For high temperature level (1500 K), the alkanes formation is lower than at lower temperature, which is balanced by the alkenes one. This fact will be discussed in next section by differentiating light and heavy alkenes whose formation and consumption is not necessarily linked. The application of these results to the hybrid engine technology and their fundamental analysis to improve the use of kinetic chemistry will be detailed.

\section{Figure 6 should be placed here Figure 7 should be placed here}

\subsection{Quantification of parameters effects}

The data have been then post-processed according to the design of experiments (example for ethylene in Table 4). The parameter levels are those defined in section 2.2 (Table 1). The ethylene content is the one measured experimentally (given in Table 3). The answer to each parameter (last line of each parameter column) is quantified by considering the sum of the eight scalar products (eight test lines in Table 4$)$ between the parameter level $(+1$ or 1) and the mole fraction of ethylene corresponding to the same test number (last column of Table 4). The main effect appears to be the atmosphere (68.3\% in absolute value), then the heating rate, the pressure and finally the temperature. All these parameters have major impact since they clearly overpass the mean ethylene mole fraction ( $9.0 \%$ is computed as the mean value of the eight line results in the ethylene column). The fact that the temperature effect is negative demonstrates that at $1500 \mathrm{~K}$, ethylene starts to be pyrolysed (as expressed when comparing tests 1 and 7 or 2 and 8 for example). The same qualitative effect is found with the atmosphere (air instead of He) while the opposite is found for the pressure and the heating rate. Similar work has been achieved for the parameters interactions without clear trends, which would tend to demonstrate that these parameters are independent. Nevertheless, an extended work would be necessary to clearly state on this point since the quantification of interactions with a two-level or three-level design of experiments would require additional tests. 


\section{Table 4 should be placed here}

The results of the design of experiments are summarized for all the species in Table 5. The higher effects are found for ethylene and propylene, then for ethane and propane. The pressure effect is then the highest for the alkenes from $\mathrm{C} 9$ to $\mathrm{C} 12$ (in absolute value, negative sign), which implicates that related $\beta$-scission reactions are penalised at high pressure. To the opposite, the higher heating rate generally favours the alkenes formation (mostly the light ones). The heavier species (C12 and over) are not impacted to the opposite by the heating rate. As a consequence, the overall effect of the heating rate is the one observed in Figure 8. This result is of major importance because this confirms previous results from numerical and experimental multiphysics studies [22], [31]. The light alkenes are formed preferably when the fuel is heated strongly and rapidly; that is to say when the heating rate is high. This point has a direct connection with hybrid rocket since producing light alkenes will result in the decrease of the autoignition delay. Thus, the flame front will establish close to the reducer surface and this should enhance the heat transfers, so the regression rate of the fuel.

Regarding the atmosphere, it mostly impacts the light species in the sense of consumption when considering air. This is directly due to their combustion due to lower auto-ignition delays compared to other and heavier compounds. Among the 42 species, the pressure effect is the major one for 34 compounds (mainly for those over C7) and the heating rate is the second important parameter for 25 species among these 42 ones. The atmosphere is the major parameter for the lighter species (from $\mathrm{C} 2 \mathrm{H} 4$ to $\mathrm{C} 7 \mathrm{H} 14$ ). Surprisingly, the temperature is not the major parameter in the range $1000 \mathrm{~K}-1500 \mathrm{~K}$ for the studied species but this does not imply that temperature is not an important parameter. Indeed, the temperature presents a higher effect that the mean mole fraction value for 28 species among the 42, which means that it is, in majority, an important parameter. In addition, the pyrolysis appears at much lower temperature than $1000 \mathrm{~K}$ (as seen in section 3.1) and this contributed to explain the lower weight of the temperature in these specific conditions.

\section{Table 5 should be placed here}

\section{Conclusion}

Among several applications, hybrid rocket propulsion can take benefice from HDPE pyrolysis studies to estimate the production of species and their nature for later use in combustion. The present study aims at proposing adequate results within this framework. The HDPE pyrolysis rate as been estimated under steady-state TG experiments. The regression rate has been determined as a function of the temperature under inert and oxidative conditions. The 
oxidation of the products has been shown and it results in a discrepancy of several factors of magnitude between the two atmospheres results. The regression rate appears quite low in TG tests (one to two orders of magnitude compared to real hybrid tests). This is attributed to the low heating rate, temperature and pressure. Thus, using a GCMS-flash pyrolysis coupling, the conditions of a hybrid engine have been choose to estimate the parameters effects through a design of experiments from $1000 \mathrm{~K}$ to $1500 \mathrm{~K}, 0.1 \mathrm{MPa}$ to $3 \mathrm{MPa}, 10^{2} \mathrm{~K} \cdot \mathrm{s}^{-1}$ to $2.10^{4} \mathrm{~K} \cdot \mathrm{s}^{-1}$ and under inert and oxidative atmosphere. In addition to the clear thermal effect on the pyrolysis products formation, the pressure appears as the second important parameter while the heating rate and the atmosphere also play a noticeable role (in this order of importance). The fact that the heating rate plays a role while the final temperature is reached after one second clearly shows the highly transient behaviour of the pyrolysis. The light alkenes are favoured at high heating rate -contrary to the dienes-, which confirms the previous results. Thanks to a design of experiment, it is found that the pressure impacts negatively the $\beta$-scission reactions. The alkanes are pyrolysed preferentially during a temperature increase, particularly for high pressure conditions. These results will now contribute to validate and to improve existing kinetic mechanisms of HDPE pyrolysis since they are unique to the authors' knowledge. Indeed, the data from literature are generally obtained and fitted for conditions up to $1000 \mathrm{~K}$, at ambient atmosphere and low heating rate (less than $1 \mathrm{~K} \cdot \mathrm{s}^{-1}$ ), which need to be improved to match with the requirements of hybrid rocket. A future work could be to use these mechanisms to determine the rate of production of compounds adequate as fuel for the hybrid engine.

\section{Acknowledgements}

The authors would like to acknowledge the Roxel company for its financial support.

\section{References}

[1] S.E. Levine, L.J. Broadbelt, Polym. Degrad. Stabil. 94 (2009) 810-822

[2] S.M. Al-Salem, P. Lettieri, Polymer chemical engineering research and design 88 (2010) 1599-1606

[3] R.W.J. Westerhout, J. Waanders, W.P.M. Van Swaaij, Ind. Eng. Chem. Res. 37 (6) (1998) 2293-2300

[4] M. D. Wallis, Suresh K. Bhatia, Polym. Degrad. Stabil., 92 (2007) 1721-1729

[5] A. Aboulkas, K. El harfi, A. El Bouadili, Thermochim. Acta 500 (2010) 30-37

[6] N. Gascoin, P. Gillard, A. Mangeot, A. Navarro-Rodriguez, J. Anal. Appl. Pyrolysis, 94 (2012) 33-40

[7] M.J. Chiaverini, K.K. Kuo, Fundamentals of hybrid rocket combustion and propulsion, vol. 218, Published by the American Institute of Aeronautics and Astronautics, Reston, Virginia.

[8] N. Gascoin, P. Gillard, A. Mangeot, A. Navarro-Rodriguez, J. Anal. Appl. Pyrolysis, 94 (2012) 1-9

[9] K. Soojong, L. Jungpyo, M. Heejang, S. Honggye, K. Jinkon, C. Jungtae. $46^{\text {th }}$ AIAA/ASME/SAE/ASEE Joint Propulsion Conference \& Exhibit, 2010, AIAA-2010-7031.

[10] J.F. Mastral, C. Berrueco, J. Ceamanos, J. Anal. Appl. Pyrolysis 79 (2007) 313-322

[11] C. Dong, Y. Yang, B. Jin, M. Horio, Waste Manage., 27(11) (2007) 1557-1561

[12] A. Németh, M. Blazso, P. Baranyai, T. Vidoczy, J. Anal. Appl. Pyrolysis 81 (2008) 237-242

[13] G. Elordi, G. Lopez, M. Olazar, R. Aguado, J. Bilbao, J. Hazard. Mater. 144 (2007) 708-714 
[14] A. Mangeot, N. Gascoin, P. Gillard, 20th AIAA Computational Fluid Dynamics Conference, 2011, AIAA2011-3212

[15] P. Grammelis, P. Basinas, A. Malliopoulou, G. Sakellaropoulos, Fuel, 88(1) (2009) 195-205

[16] M. J. De Witt, L. J. Broadbelt, Energ. Fuel. 14 (2000) 448-458

[17] I. Johannes, H. Tamvelius, L. Tiikma, J. Anal. Appl. Pyrolysis 72 (2004) 113-119

[18] P. Paik, K.K. Kar, Mater. Chem. Phys. 113 (2009) 953-961

[19] P. Budrugeac, Thermochim. Acta 500 (2010) 30-37

[20] S. Kim, E.-S. Jang, D.-H. Shin, K.-H. Lee, Polym. Degrad. Stabil., 85(2) (2004) 799-805

[21] J. Yang, R. Miranda, C. Roy, Polym. Degrad. Stabil., 73(3) (2001) 455-461.

[22] N. Gascoin, Etude et mesure de paramètres pertinents dans un écoulement réactif application au refroidissement par endo-carburant d'un super-statoréacteur, Editions Universitaires Européennes, April 2010, ISBN13: 978-6131501074, p.376

[23] N. Gascoin, A. Navarro-Rodriguez, G. Fau, P.Gillard, Polym. Degrad. Stabil., 97 (2012) 1142-1150

[24] T. P. Wampler, Applied Pyrolysis Handbook, 2007 Taylor \& Francis Group LLC

[25] T.P. Wampler, E.J. Levy, J. Anal. Appl. Pyrolysis, 8 (1985), 153-161

[26] T. Hayakawa, S. Kageyama, M.L. Puri, J. Stat. Plan. Infer. 138 (11) (2008) 3293.

[27] A. Mangeot, Étude expérimentale et développement numérique d'une modélisation des phénomènes physicochimiques dans un propulseur hybride spatial, Ph.D. Thesis, December 2012, University of Orléans, France.

[28] G. Abraham, Etude et développement d'une méthode d'analyse par spectroscopie infrarouge appliquée à la pyrolyse d'hydrocarbures en conditions supercritiques et transitoires, Ph.D. Thesis, University of Orléans, France, December 2009

[29] International Security data for HDPE, http://www.cdc.gov/niosh/ipcsnfrn/nfrn1488.html, last accessed 11/01/2013

[30] O. Senneca, R. Chirone, P. Salatino, J. Anal. Appl. Pyrol, 71(2) (2004) 959-970

[31] G. Fau, N. Gascoin, P. Gillard, M. Bouchez, J. Steelant, J. Anal. Appl. Pyrol., 95 (2012) 180-188 
Table 1. List and levels of physical parameters of the design of experiments.

Table 2. TG pyrolysis data of HDPE under inert and oxidative conditions.

Table 3. Mole fractions (mol. \%) of HDPE pyrolysis products under corresponding test conditions.

Table 4. Example of data post-processing according to the design of experiments for ethylene formation.

Table 5. Parameters effect on the formation of pyrolysis products (in mol. \%).

Figure 1.Reproducibility tests on TG analysis under inert atmosphere at $420^{\circ} \mathrm{C}$ with different sample size (a) and on Flash Pyrolysis (b).

Figure 2. TGA mass loss divided by the sample mass under oxidative atmosphere.

Figure 3. Regression rate measured by TG (a) and converted in mm.s-1 for hybrid rocket application (b). Figure 4. Mass spectrogram of HDPE pyrolysis mixtures obtained at $20000 \mathrm{~K} / \mathrm{s}$ for some test conditions.

Figure 5. Formation of alkenes, alkanes and dienes under inert and oxidative atmosphere.

Figure 6. Formation of alkenes, alkanes and dienes at two pressure levels.

Figure 7. Formation of alkenes, alkanes and dienes at two heating rates. 
Table 1. List and levels of physical parameters of the design of experiments

\begin{tabular}{ccccc}
\hline \hline Level of parameter & Heating rate $\left({\left.\mathrm{K} . \mathrm{s}^{-1}\right)}^{-}\right.$ & Pressure (MPa) & Reactant Gas & Setup Temperature (K) \\
\hline-1 & 100 & 0.1 & Inert (He) & 1000 \\
- & - & - & - & 1250 \\
+1 & 20000 & 3.0 & Oxidative (air) & 1500 \\
\hline \hline
\end{tabular}

349 
Table 2. TG pyrolysis data of HDPE under inert and oxidative conditions.

\begin{tabular}{|c|c|c|c|c|c|c|}
\hline \multirow{2}{*}{$\begin{array}{c}\text { Setup } \\
\text { temperature } \\
\text { (K) }\end{array}$} & \multicolumn{3}{|c|}{ Inert (Argon) } & \multicolumn{3}{|c|}{ Oxidative (Air) } \\
\hline & $\begin{array}{c}\text { Pyrolysis } \\
\text { rate (wt.\%) }\end{array}$ & $\begin{array}{c}\text { Regression } \\
\text { rate } \\
\left(\mathrm{mg}^{-1} \mathrm{~s}^{-1}\right)\end{array}$ & $\begin{array}{c}\text { Regression } \\
\text { rate } \\
\left(\mathrm{mm}^{-1} \mathbf{s}^{-1}\right)\end{array}$ & $\begin{array}{c}\text { Pyrolysis } \\
\text { rate (wt.\%) }\end{array}$ & $\begin{array}{c}\text { Regression } \\
\text { rate } \\
\left.\left(\mathrm{mg}^{-1}\right)^{-1}\right)\end{array}$ & $\begin{array}{c}\text { Regression } \\
\text { rate } \\
\left(\mathrm{mm} \cdot \mathrm{s}^{-1}\right)\end{array}$ \\
\hline 633 & $8 \%$ & $1.9 .10^{-4}$ & $4.7 .10^{-5}$ & $13 \%$ & $5.9 .10^{-4}$ & $7.6 .10^{-5}$ \\
\hline 653 & $39 \%$ & $3.0 .10^{-4}$ & $6.6 .10^{-5}$ & $41 \%$ & $7.9 .10^{-4}$ & $1.6 .10^{-4}$ \\
\hline 673 & $88 \%$ & $4.5 .10^{-4}$ & $8.1 .10^{-5}$ & $91 \%$ & $2.2 .10^{-3}$ & $3.5 .10^{-4}$ \\
\hline 693 & $91 \%$ & $3.3 .10^{-3}$ & $1.7 .10^{-4}$ & $91 \%$ & $3.2 .10^{-3}$ & $5.5 .10^{-4}$ \\
\hline 713 & $100 \%$ & $1.4 .10^{-3}$ & $3.0 .10^{-4}$ & $97 \%$ & $1.6 .10^{-2}$ & $1.2 .10^{-3}$ \\
\hline 733 & $100 \%$ & $2.9 .10^{-3}$ & $4.6 .10^{-4}$ & $100 \%$ & $4.0 .10^{-2}$ & $2.9 .10^{-3}$ \\
\hline 773 & $100 \%$ & $2.2 .10^{-2}$ & $1.4 .10^{-3}$ & $100 \%$ & $1.5 .10^{-1}$ & $9.3 .10^{-3}$ \\
\hline
\end{tabular}


Table 3. Mole fractions (mol. \%) of HDPE pyrolysis products under corresponding test conditions.

\begin{tabular}{|c|c|c|c|c|c|c|c|c|c|c|c|c|c|}
\hline & Test number: & 1 & 2 & 3 & 4 & 5 & 6 & 7 & 8 & 9 & 10 & 11 & 12 \\
\hline Species & $\begin{array}{c}\text { Molecular } \\
\text { weight } \\
\left(\mathrm{g} \cdot \mathrm{mol}^{-1}\right)\end{array}$ & $\begin{array}{c}1000 \mathrm{~K} \\
1 \mathrm{bar} \mathrm{He} \\
2.10^{4} \mathrm{~K} / \mathrm{s}\end{array}$ & $\begin{array}{c}1000 \mathrm{~K} \\
30 \mathrm{barHe} \\
2.10^{4} \mathrm{~K} / \mathrm{s}\end{array}$ & $\begin{array}{c}1000 \mathrm{~K} \\
1 \mathrm{bar} \text { air } \\
2.10^{4} \mathrm{~K} / \mathrm{s}\end{array}$ & $\begin{array}{c}1250 \mathrm{~K} \\
1 \mathrm{bar} \mathrm{He} \\
2.10^{4} \mathrm{~K} / \mathrm{s}\end{array}$ & $\begin{array}{c}1250 \mathrm{~K} \\
30 \mathrm{barHe} \\
2.10^{4} \mathrm{~K} / \mathrm{s}\end{array}$ & $\begin{array}{c}1250 \mathrm{~K} \\
1 \mathrm{bar} \text { air } \\
2.10^{4} \mathrm{~K} / \mathrm{s}\end{array}$ & $\begin{array}{c}1500 \mathrm{~K} \\
1 \mathrm{bar} \mathrm{He} \\
2.10^{4} \mathrm{~K} / \mathrm{s}\end{array}$ & $\begin{array}{c}1500 \mathrm{~K} \\
30 \mathrm{barHe} \\
2.10^{4} \mathrm{~K} / \mathrm{s}\end{array}$ & $\begin{array}{c}1500 \mathrm{~K} \\
1 \mathrm{bar} \text { air } \\
2.10^{4} \mathrm{~K} / \mathrm{s}\end{array}$ & $\begin{array}{c}1000 \mathrm{~K} \\
1 \mathrm{bar} \mathrm{He} \\
100 \mathrm{~K} / \mathrm{s}\end{array}$ & $\begin{array}{c}1250 \mathrm{~K} \\
1 \mathrm{bar} \mathrm{He} \\
100 \mathrm{~K} / \mathrm{s}\end{array}$ & $\begin{array}{c}1500 \mathrm{~K} \\
1 \mathrm{bar} \mathrm{He} \\
100 \mathrm{~K} / \mathrm{s}\end{array}$ \\
\hline $\mathrm{CH} 4$ & 16 & 0.00 & 0.00 & 0.00 & 0.00 & 0.00 & 0.00 & 0.00 & 0.00 & 0.00 & 0.00 & 0.00 & 0.00 \\
\hline $\mathrm{C} 2 \mathrm{H} 2$ & 26 & 0.00 & 0.00 & 0.00 & 0.00 & 0.07 & 0.00 & 0.00 & 0.00 & 0.00 & 0.00 & 0.00 & 0.00 \\
\hline $\mathrm{C} 2 \mathrm{H} 4$ & 28 & 3.20 & 45.95 & 0.97 & 1.40 & 38.38 & 0.85 & 1.33 & 14.78 & 0.76 & 0.49 & 1.58 & 4.28 \\
\hline $\mathrm{C} 2 \mathrm{H} 6$ & 30 & 1.19 & 18.47 & 0.58 & 0.40 & 13.50 & 0.20 & 0.42 & 8.27 & 0.18 & 0.30 & 0.66 & 1.16 \\
\hline $\mathrm{C} 3 \mathrm{H} 6$ & 42 & 9.98 & 12.41 & 10.64 & 8.09 & 7.52 & 11.96 & 10.94 & 11.04 & 10.75 & 5.51 & 7.85 & 17.52 \\
\hline $\mathrm{C} 3 \mathrm{H} 8$ & 44 & 9.66 & 2.98 & 5.98 & 3.41 & 2.89 & 4.54 & 6.31 & 4.71 & 4.08 & 4.68 & 4.88 & 4.32 \\
\hline $\mathrm{C} 4 \mathrm{H} 8$ & 56 & 2.01 & 1.78 & 3.73 & 3.61 & 0.60 & 5.82 & 2.25 & 3.09 & 5.23 & 1.81 & 3.04 & 10.58 \\
\hline $\mathrm{C} 4 \mathrm{H} 10$ & 58 & 1.94 & 0.34 & 0.15 & 0.48 & 0.10 & 0.70 & 0.63 & 0.27 & 0.63 & 0.49 & 0.43 & 0.38 \\
\hline C5H10 & 70 & 0.80 & 0.25 & 0.29 & 0.20 & 0.32 & 0.30 & 0.00 & 0.56 & 0.27 & 0.07 & 0.15 & 0.94 \\
\hline C5H12 & 72 & 0.00 & 0.28 & 0.47 & 0.36 & 0.34 & 0.54 & 0.46 & 0.36 & 0.48 & 0.47 & 0.54 & 0.44 \\
\hline C6H12 & 84 & 1.46 & 3.92 & 0.79 & 2.98 & 7.66 & 4.77 & 3.18 & 12.89 & 4.29 & 0.65 & 2.36 & 5.63 \\
\hline C6H14 & 86 & 1.73 & 0.17 & 0.73 & 0.62 & 0.23 & 0.63 & 0.84 & 0.29 & 0.57 & 0.83 & 0.91 & 0.61 \\
\hline C7H14 & 96 & 1.50 & 0.64 & 0.18 & 0.28 & 0.67 & 0.25 & 0.09 & 1.56 & 0.22 & 0.06 & 0.17 & 0.54 \\
\hline C7H16 & 98 & 0.55 & 0.12 & 0.81 & 0.64 & 0.15 & 0.59 & 0.72 & 0.24 & 0.53 & 0.77 & 0.82 & 0.59 \\
\hline C8 & 113 & 0.00 & 0.00 & 8.10 & 5.55 & 0.00 & 5.50 & 4.90 & 4.62 & 2.67 & 0.89 & 6.48 & 1.68 \\
\hline С9H16 & 124 & 0.00 & 0.00 & 1.31 & 0.92 & 0.00 & 0.00 & 0.00 & 0.00 & 1.81 & 0.00 & 0.00 & 0.98 \\
\hline С9H18 & 126 & 12.20 & 2.86 & 2.64 & 4.49 & 2.45 & 9.31 & 6.48 & 6.51 & 8.47 & 9.52 & 9.75 & 5.03 \\
\hline С9H20 & 128 & 4.38 & 0.97 & 3.78 & 2.52 & 0.49 & 2.17 & 2.68 & 1.36 & 3.03 & 3.93 & 3.79 & 1.56 \\
\hline $\mathrm{C} 10 \mathrm{H} 18$ & 138 & 2.16 & 0.00 & 3.77 & 2.69 & 2.73 & 3.96 & 3.70 & 3.36 & 3.89 & 2.64 & 2.74 & 3.79 \\
\hline $\mathrm{C} 10 \mathrm{H} 20$ & 140 & 16.47 & 4.69 & 8.66 & 9.25 & 6.51 & 9.81 & 14.40 & 7.30 & 9.52 & 11.80 & 12.44 & 9.12 \\
\hline $\mathrm{C} 10 \mathrm{H} 22$ & 142 & 8.05 & 1.52 & 3.96 & 2.57 & 1.81 & 2.82 & 4.63 & 1.58 & 3.45 & 4.01 & 4.11 & 1.64 \\
\hline C11H20 & 152 & 0.00 & 0.00 & 2.26 & 1.74 & 1.76 & 2.54 & 1.73 & 2.00 & 2.29 & 1.70 & 1.86 & 2.34 \\
\hline $\mathrm{C} 11 \mathrm{H} 22$ & 154 & 7.58 & 1.99 & 5.03 & 5.43 & 3.94 & 5.68 & 7.42 & 4.07 & 5.46 & 6.47 & 6.54 & 4.86 \\
\hline $\mathrm{C} 11 \mathrm{H} 24$ & 156 & 6.31 & 0.61 & 4.12 & 2.69 & 1.84 & 2.57 & 4.58 & 1.51 & 3.18 & 4.17 & 4.44 & 1.57 \\
\hline $\mathrm{C} 12 \mathrm{H} 22$ & 166 & 0.00 & 0.00 & 2.13 & 1.48 & 1.25 & 1.96 & 1.40 & 1.79 & 2.08 & 1.25 & 1.40 & 2.21 \\
\hline $\mathrm{C} 12 \mathrm{H} 24$ & 168 & 1.19 & 0.00 & 2.90 & 2.47 & 1.73 & 2.36 & 2.49 & 2.07 & 2.68 & 2.91 & 2.77 & 2.28 \\
\hline $\mathrm{C} 12 \mathrm{H} 26$ & 170 & 1.87 & 0.00 & 3.16 & 2.24 & 1.20 & 2.47 & 2.68 & 1.01 & 1.99 & 3.08 & 2.87 & 1.16 \\
\hline $\mathrm{C} 13 \mathrm{H} 24$ & 180 & 0.00 & 0.00 & 2.04 & 1.42 & 0.59 & 1.26 & 0.58 & 1.05 & 1.67 & 1.02 & 0.96 & 1.47 \\
\hline $\mathrm{C} 13 \mathrm{H} 26$ & 182 & 0.00 & 0.00 & 2.53 & 1.83 & 0.73 & 1.43 & 0.89 & 1.16 & 2.00 & 1.81 & 1.64 & 1.46 \\
\hline $\mathrm{C} 13 \mathrm{H} 28$ & 184 & 0.00 & 0.00 & 2.27 & 1.12 & 0.46 & 0.72 & 1.13 & 0.49 & 1.33 & 1.45 & 1.38 & 0.59 \\
\hline $\mathrm{C} 14 \mathrm{H} 26$ & 194 & 0.00 & 0.00 & 1.74 & 0.98 & 0.08 & 1.10 & 0.00 & 0.52 & 1.49 & 0.73 & 0.61 & 0.90 \\
\hline C14H28 & 196 & 0.00 & 0.00 & 2.10 & 1.52 & 0.00 & 1.06 & 1.14 & 0.52 & 1.67 & 1.52 & 1.31 & 1.00 \\
\hline C15 & 210 & 1.77 & 0.00 & 2.17 & 2.64 & 0.00 & 2.44 & 3.25 & 1.00 & 2.32 & 3.06 & 1.85 & 1.66 \\
\hline $\mathrm{C} 16$ & 224 & 1.78 & 0.00 & 1.96 & 2.52 & 0.00 & 1.69 & 1.81 & 0.00 & 1.78 & 2.81 & 0.73 & 1.25 \\
\hline $\mathrm{C} 17$ & 238 & 1.79 & 0.00 & 2.24 & 2.44 & 0.00 & 1.94 & 2.13 & 0.00 & 1.80 & 2.44 & 1.47 & 1.12 \\
\hline $\mathrm{C} 18$ & 252 & 0.43 & 0.00 & 1.77 & 2.60 & 0.00 & 1.26 & 1.01 & 0.00 & 1.72 & 2.43 & 0.65 & 0.93 \\
\hline $\mathrm{C} 19$ & 267 & 0.00 & 0.00 & 1.31 & 2.60 & 0.00 & 1.05 & 1.67 & 0.00 & 1.03 & 2.24 & 0.58 & 0.70 \\
\hline $\mathrm{C} 20$ & 281 & 0.00 & 0.00 & 1.39 & 2.80 & 0.00 & 0.58 & 0.74 & 0.00 & 0.89 & 3.07 & 0.44 & 0.60 \\
\hline $\mathrm{C} 21$ & 295 & 0.00 & 0.00 & 1.05 & 4.26 & 0.00 & 0.60 & 0.47 & 0.00 & 1.52 & 3.46 & 1.49 & 0.55 \\
\hline $\mathrm{C} 22$ & 309 & 0.00 & 0.00 & 0.20 & 2.76 & 0.00 & 1.59 & 0.76 & 0.00 & 0.95 & 2.82 & 1.96 & 0.89 \\
\hline $\mathrm{C} 23$ & 323 & 0.00 & 0.00 & 0.00 & 2.30 & 0.00 & 0.76 & 0.00 & 0.00 & 0.77 & 2.12 & 1.44 & 0.59 \\
\hline $\mathrm{C} 24$ & 337 & 0.00 & 0.00 & 0.00 & 1.48 & 0.00 & 0.14 & 0.00 & 0.00 & 0.47 & 0.16 & 0.82 & 0.75 \\
\hline $\mathrm{C} 25$ & 351 & 0.00 & 0.00 & 0.00 & 0.08 & 0.00 & 0.00 & 0.00 & 0.00 & 0.00 & 0.30 & 0.00 & 0.27 \\
\hline \multirow[t]{4}{*}{$\mathrm{C} 26$} & 365 & 0.00 & 0.00 & 0.00 & 0.00 & 0.00 & 0.00 & 0.00 & 0.00 & 0.00 & 0.00 & 0.00 & 0.00 \\
\hline & Alkanes & 35.68 & 25.47 & 26.01 & 17.04 & 22.98 & 17.95 & 25.07 & 20.09 & 19.45 & 24.17 & 24.83 & 14.03 \\
\hline & Alkenes & 62.17 & 74.48 & 60.65 & 73.60 & 70.52 & 71.13 & 67.36 & 71.17 & 67.24 & 68.44 & 67.52 & 74.23 \\
\hline & Dienes & 2.16 & 0.00 & 13.26 & 9.23 & 6.48 & 10.82 & 7.41 & 8.72 & 13.23 & 7.35 & 7.58 & 11.69 \\
\hline
\end{tabular}


354 Table 4. Example of data post-processing according to the design of experiments for ethylene formation.

\begin{tabular}{|c|c|c|c|c|c|}
\hline $\begin{array}{l}\text { Test number } \\
\text { (see Table 3) }\end{array}$ & Pressure & Temperature & Heating rate & Atmosphere & $\begin{array}{c}\mathrm{C} 2 \mathrm{H} 4 \\
\text { mole } \\
\text { fraction }\end{array}$ \\
\hline 1 & -1 & -1 & +1 & -1 & $3.2 \%$ \\
\hline 2 & +1 & -1 & +1 & -1 & $45.9 \%$ \\
\hline 3 & -1 & -1 & +1 & +1 & $1.0 \%$ \\
\hline 7 & -1 & +1 & +1 & -1 & $1.3 \%$ \\
\hline 8 & +1 & +1 & +1 & -1 & $14.8 \%$ \\
\hline 9 & -1 & +1 & +1 & +1 & $0.8 \%$ \\
\hline 10 & -1 & -1 & -1 & -1 & $0.5 \%$ \\
\hline 12 & -1 & +1 & -1 & -1 & $4.3 \%$ \\
\hline $\begin{array}{r}\text { Parameters } \\
\text { effects : }\end{array}$ & $49.7 \%$ & $-29.5 \%$ & $62.2 \%$ & $-68.3 \%$ & $9.0 \%$ \\
\hline
\end{tabular}


Table 5. Parameters effect on the formation of pyrolysis products (in mol. \%).

\begin{tabular}{|c|c|c|c|c|c|}
\hline & Pressure & Temperature & Heating rate & Atmosphere & $\begin{array}{l}\text { Mean mole } \\
\text { fraction }\end{array}$ \\
\hline $\mathrm{C} 2 \mathrm{H} 4$ & $49.7 \%$ & $-29.5 \%$ & $62.2 \%$ & $-68.3 \%$ & $9.0 \%$ \\
\hline $\mathrm{C} 2 \mathrm{H} 6$ & $22.9 \%$ & $-10.5 \%$ & $27.6 \%$ & $-29.0 \%$ & $3.8 \%$ \\
\hline $\mathrm{C} 3 \mathrm{H} 6$ & $-41.9 \%$ & $11.7 \%$ & $42.7 \%$ & $-46.0 \%$ & $11.1 \%$ \\
\hline $\mathrm{C} 3 \mathrm{H} 8$ & $-27.3 \%$ & $-3.9 \%$ & $24.7 \%$ & $-22.6 \%$ & $5.3 \%$ \\
\hline $\mathrm{C} 4 \mathrm{H} 8$ & $-20.75 \%$ & $11.81 \%$ & $5.70 \%$ & $-12.55 \%$ & $3.81 \%$ \\
\hline $\mathrm{C} 4 \mathrm{H} 10$ & $-3.6 \%$ & $-1.0 \%$ & $3.1 \%$ & $-3.3 \%$ & $0.6 \%$ \\
\hline $\mathrm{C} 5 \mathrm{H} 10$ & $-1.5 \%$ & $0.4 \%$ & $1.2 \%$ & $-2.1 \%$ & $0.4 \%$ \\
\hline $\mathrm{C} 5 \mathrm{H} 12$ & $-1.7 \%$ & $0.5 \%$ & $1.2 \%$ & $-1.1 \%$ & $0.4 \%$ \\
\hline $\mathrm{C} 6 \mathrm{H} 12$ & $0.8 \%$ & $19.2 \%$ & $20.3 \%$ & $-22.7 \%$ & $4.1 \%$ \\
\hline $\mathrm{C} 6 \mathrm{H} 14$ & $-4.8 \%$ & $-1.1 \%$ & $2.9 \%$ & $-3.2 \%$ & $0.7 \%$ \\
\hline $\mathrm{C} 7 \mathrm{H} 14$ & $-0.4 \%$ & $0.0 \%$ & $3.6 \%$ & $-4.0 \%$ & $0.6 \%$ \\
\hline $\mathrm{C} 7 \mathrm{H} 16$ & $-3.6 \%$ & $-0.2 \%$ & $1.6 \%$ & $-1.6 \%$ & $0.5 \%$ \\
\hline C8 & $-13.6 \%$ & $4.9 \%$ & $17.7 \%$ & $-1.3 \%$ & $2.9 \%$ \\
\hline $\mathrm{C} 9 \mathrm{H} 16$ & $-4.1 \%$ & $1.5 \%$ & $2.1 \%$ & $2.1 \%$ & $0.5 \%$ \\
\hline $\mathrm{C} 9 \mathrm{H} 18$ & $-35.0 \%$ & $-0.7 \%$ & $24.6 \%$ & $-31.5 \%$ & $6.7 \%$ \\
\hline $\mathrm{C} 9 \mathrm{H} 20$ & $-17.0 \%$ & $-4.4 \%$ & $10.7 \%$ & $-8.1 \%$ & $2.7 \%$ \\
\hline C10H18 & $-16.6 \%$ & $6.2 \%$ & $10.4 \%$ & $-8.0 \%$ & $2.9 \%$ \\
\hline $\mathrm{C} 10 \mathrm{H} 20$ & $-58.0 \%$ & $-1.3 \%$ & $40.1 \%$ & $-45.6 \%$ & $10.2 \%$ \\
\hline $\mathrm{C} 10 \mathrm{H} 22$ & $-22.6 \%$ & $-6.2 \%$ & $17.5 \%$ & $-14.0 \%$ & $3.6 \%$ \\
\hline $\mathrm{C} 11 \mathrm{H} 20$ & $-8.3 \%$ & $4.4 \%$ & $4.2 \%$ & $-3.2 \%$ & $1.5 \%$ \\
\hline C11H22 & $-30.8 \%$ & $0.7 \%$ & $20.2 \%$ & $-21.9 \%$ & $5.4 \%$ \\
\hline $\mathrm{C} 11 \mathrm{H} 24$ & $-21.8 \%$ & $-4.4 \%$ & $14.6 \%$ & $-11.4 \%$ & $3.3 \%$ \\
\hline $\mathrm{C} 12 \mathrm{H} 22$ & $-7.3 \%$ & $4.1 \%$ & $3.9 \%$ & $-2.4 \%$ & $1.4 \%$ \\
\hline $\mathrm{C} 12 \mathrm{H} 24$ & $-12.4 \%$ & $2.5 \%$ & $6.1 \%$ & $-5.4 \%$ & $2.1 \%$ \\
\hline $\mathrm{C} 12 \mathrm{H} 26$ & $-12.9 \%$ & $-1.3 \%$ & $6.5 \%$ & $-4.7 \%$ & $1.9 \%$ \\
\hline $\mathrm{C} 13 \mathrm{H} 24$ & $-5.7 \%$ & $1.7 \%$ & $2.9 \%$ & $-0.4 \%$ & $1.0 \%$ \\
\hline $\mathrm{C} 13 \mathrm{H} 26$ & $-7.5 \%$ & $1.2 \%$ & $3.3 \%$ & $-0.8 \%$ & $1.2 \%$ \\
\hline $\mathrm{C} 13 \mathrm{H} 28$ & $-6.3 \%$ & $-0.2 \%$ & $3.2 \%$ & $-0.1 \%$ & $0.9 \%$ \\
\hline $\mathrm{C} 14 \mathrm{H} 26$ & $-4.3 \%$ & $0.4 \%$ & $2.1 \%$ & $1.1 \%$ & $0.7 \%$ \\
\hline C14H28 & $-6.9 \%$ & $0.7 \%$ & $2.9 \%$ & $-0.4 \%$ & $1.0 \%$ \\
\hline C15 & $-13.2 \%$ & $1.2 \%$ & $5.8 \%$ & $-6.3 \%$ & $1.9 \%$ \\
\hline C16 & $-11.4 \%$ & $-1.7 \%$ & $3.3 \%$ & $-3.9 \%$ & $1.4 \%$ \\
\hline C17 & $-11.5 \%$ & $-1.4 \%$ & $4.4 \%$ & $-3.5 \%$ & $1.4 \%$ \\
\hline C18 & $-8.3 \%$ & $-1.0 \%$ & $1.6 \%$ & $-1.3 \%$ & $1.0 \%$ \\
\hline C19 & $-7.0 \%$ & $-0.1 \%$ & $1.1 \%$ & $-2.3 \%$ & $0.9 \%$ \\
\hline C20 & $-6.7 \%$ & $-2.2 \%$ & $-0.7 \%$ & $-2.1 \%$ & $0.8 \%$ \\
\hline C21 & $-7.1 \%$ & $-2.0 \%$ & $-1.0 \%$ & $-1.9 \%$ & $0.9 \%$ \\
\hline C22 & $-5.6 \%$ & $-0.4 \%$ & $-1.8 \%$ & $-3.3 \%$ & $0.7 \%$ \\
\hline C23 & $-3.5 \%$ & $-0.8 \%$ & $-1.9 \%$ & $-1.9 \%$ & $0.4 \%$ \\
\hline C24 & $-1.4 \%$ & $1.1 \%$ & $-0.4 \%$ & $-0.4 \%$ & $0.2 \%$ \\
\hline C25 & $-0.6 \%$ & $0.0 \%$ & $-0.6 \%$ & $-0.6 \%$ & $0.1 \%$ \\
\hline C26 & $0.0 \%$ & $0.0 \%$ & $0.0 \%$ & $0.0 \%$ & $0.0 \%$ \\
\hline
\end{tabular}




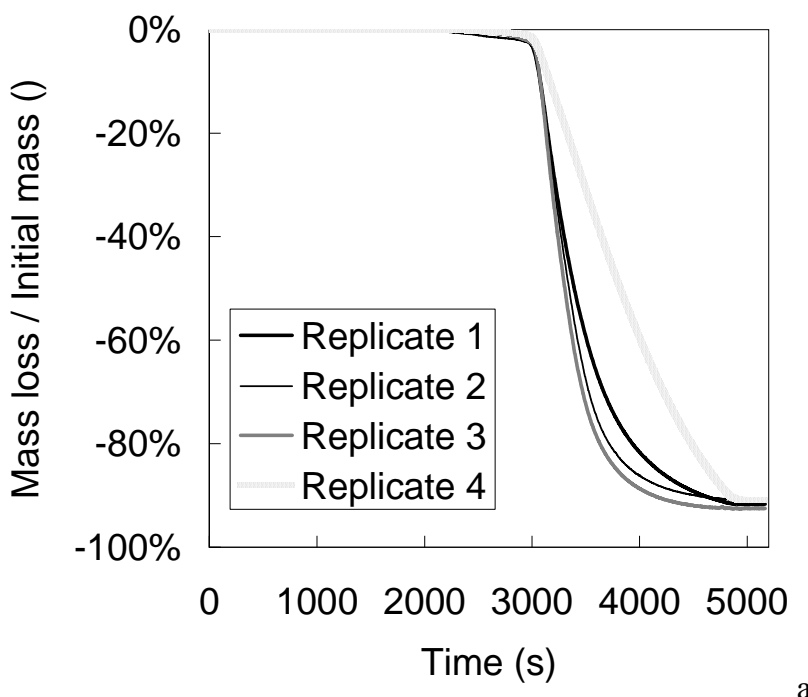

a)

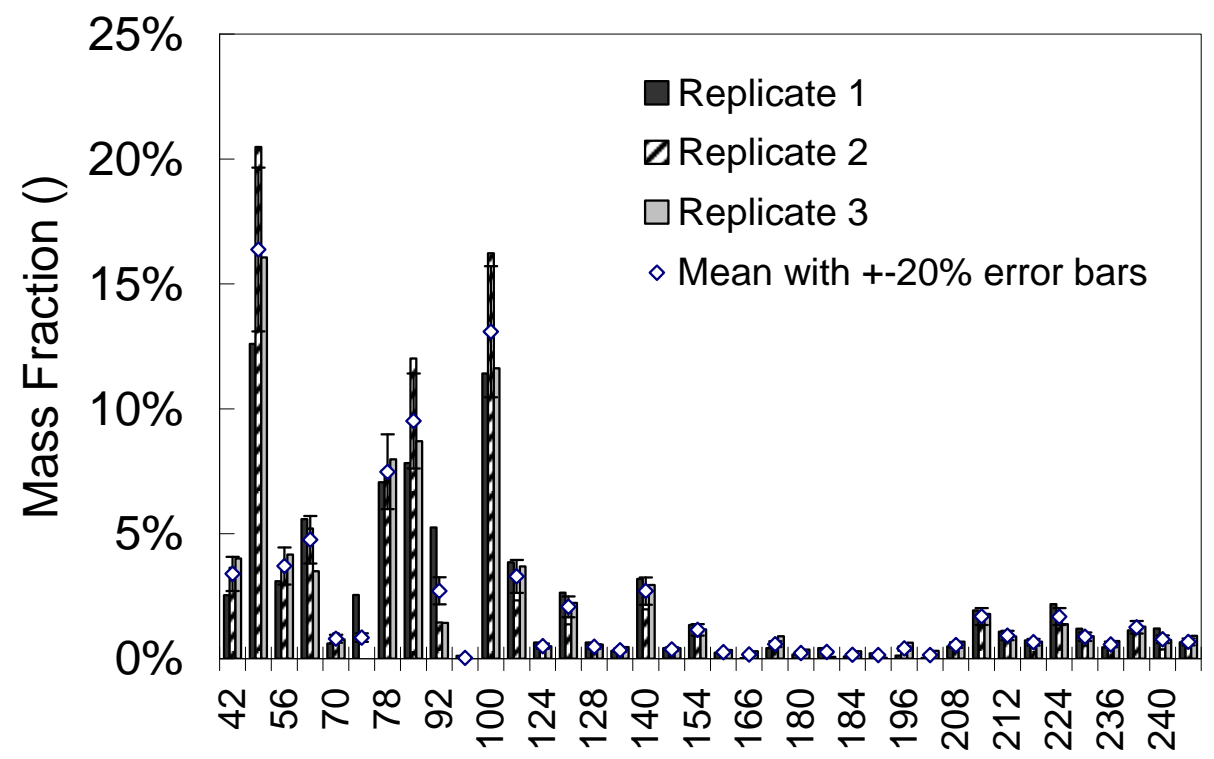
Molecular weight $\left(\mathrm{g} \cdot \mathrm{mol}^{-1}\right)$

b)

Figure 1. Reproducibility tests on TG analysis under inert atmosphere at $420{ }^{\circ} \mathrm{C}$ with different sample size (a)

and on Flash Pyrolysis (b). 


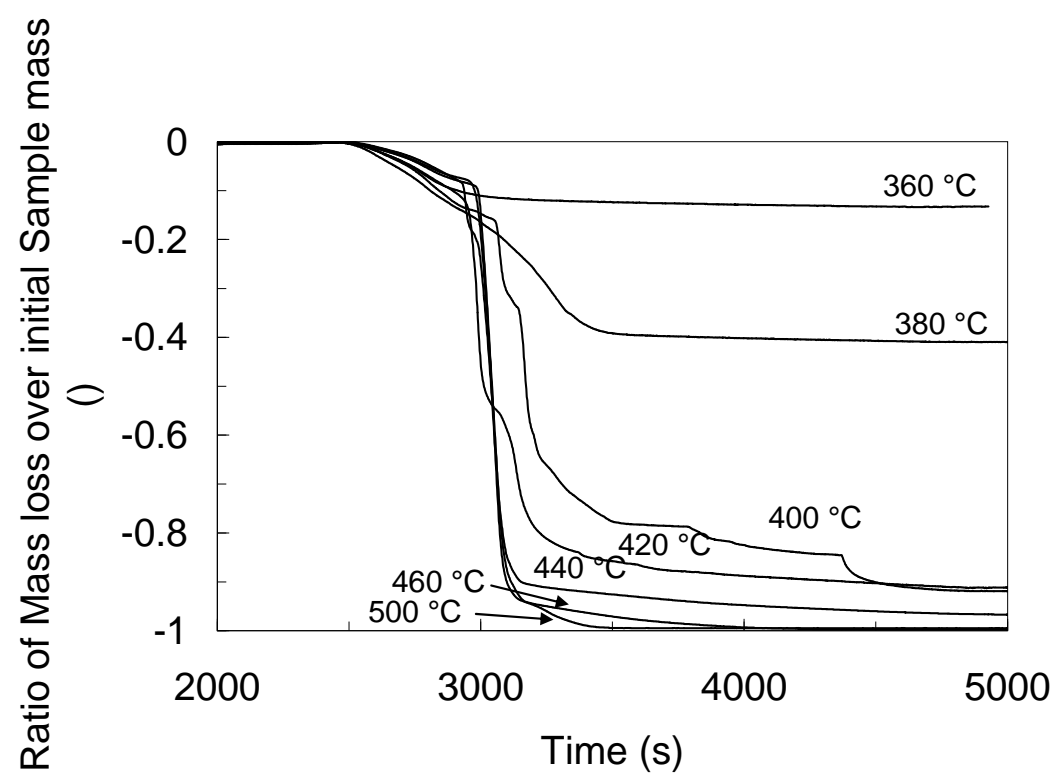

Figure 2. TGA mass loss divided by the sample mass under oxidative atmosphere. 

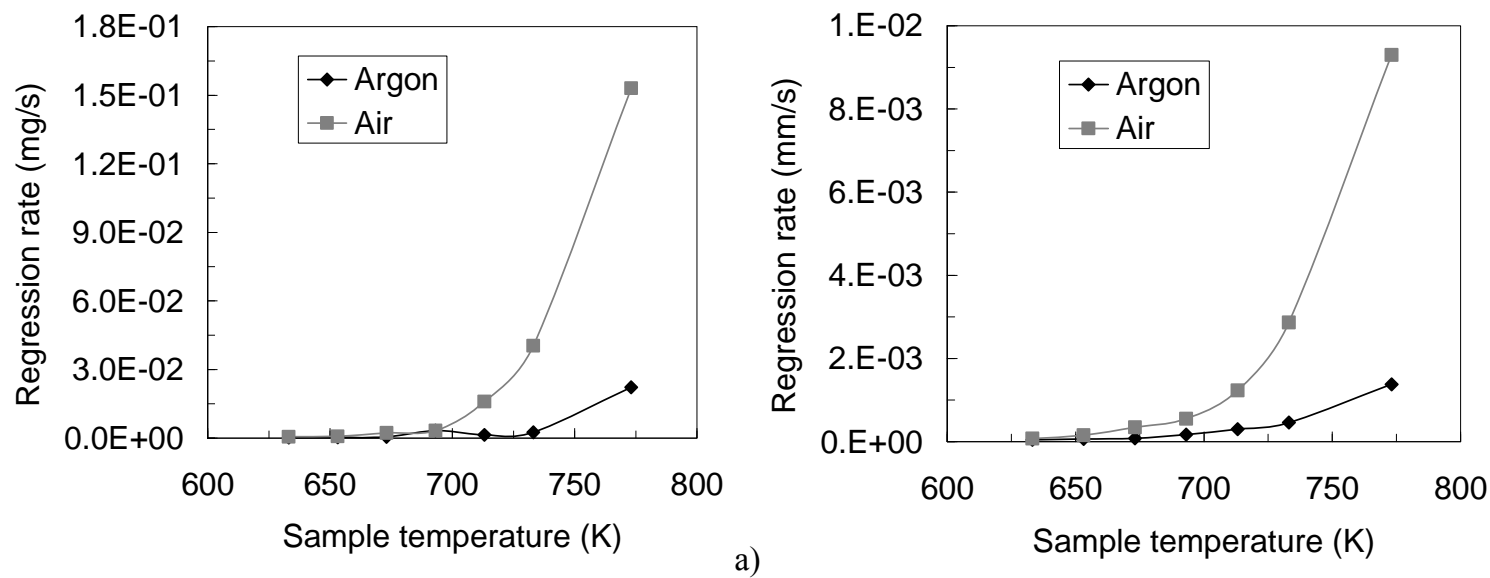

b)

Figure 3. Regression rate measured by TG (a) and converted in $\mathbf{m m} \cdot \mathrm{s}^{-1}$ for hybrid rocket application (b). 


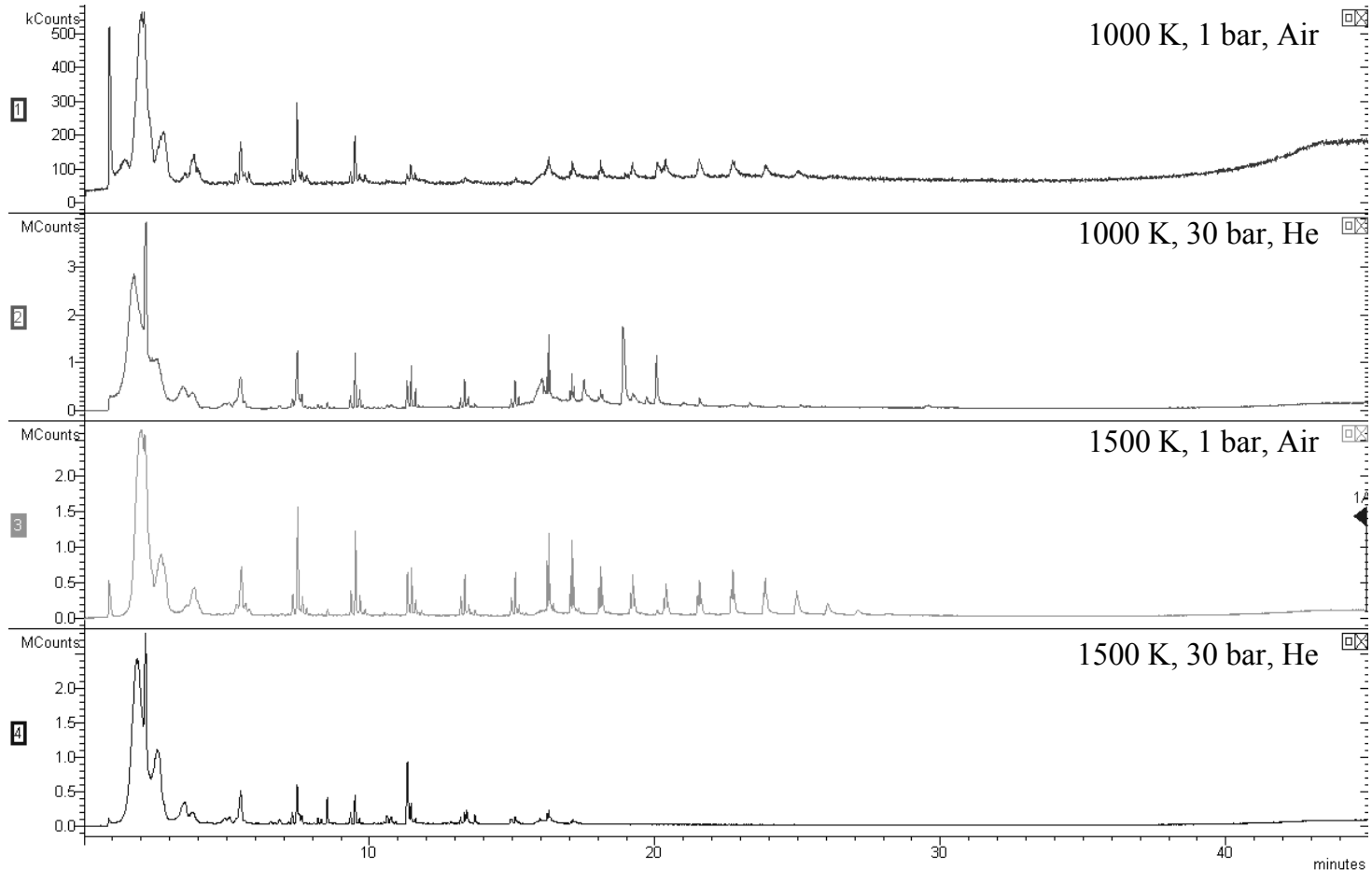




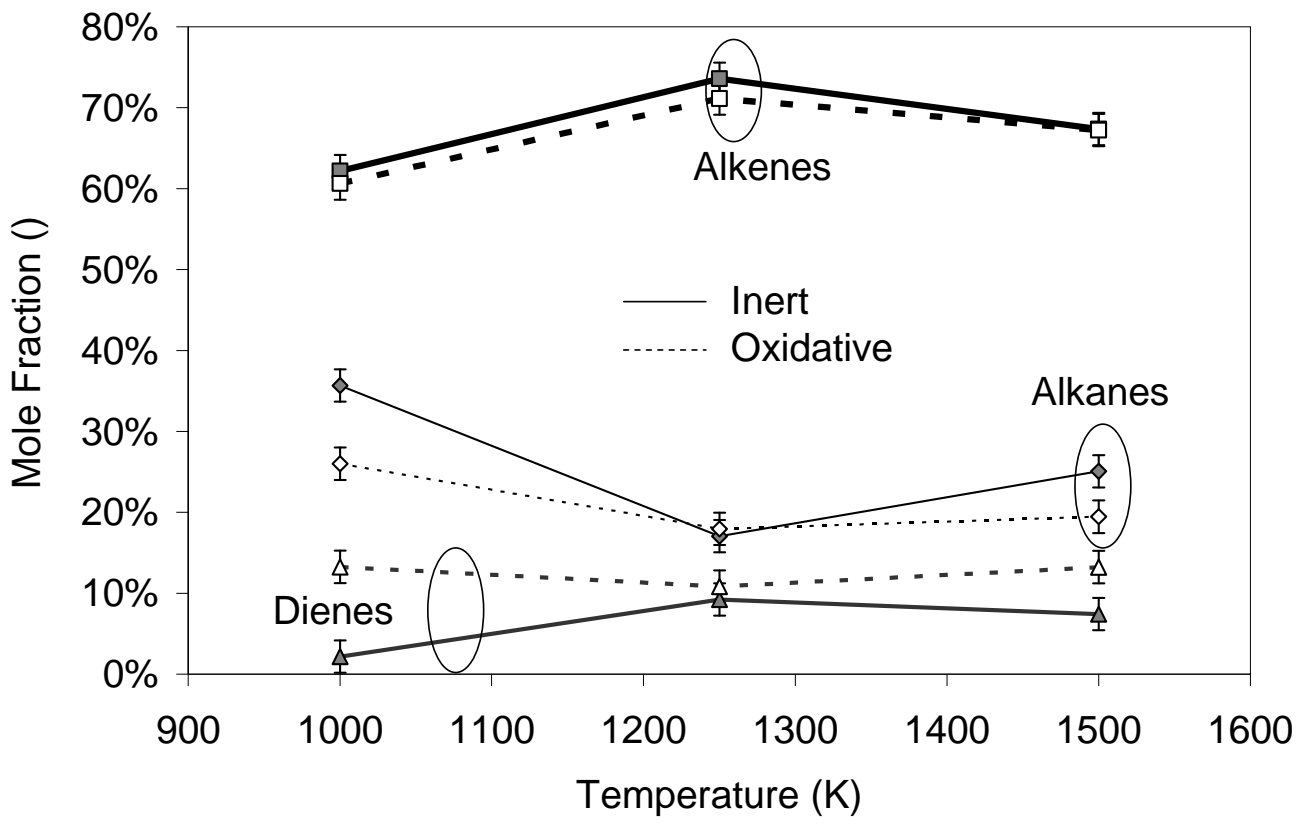

Figure 5. Formation of alkenes, alkanes and dienes under inert and oxidative atmosphere. 


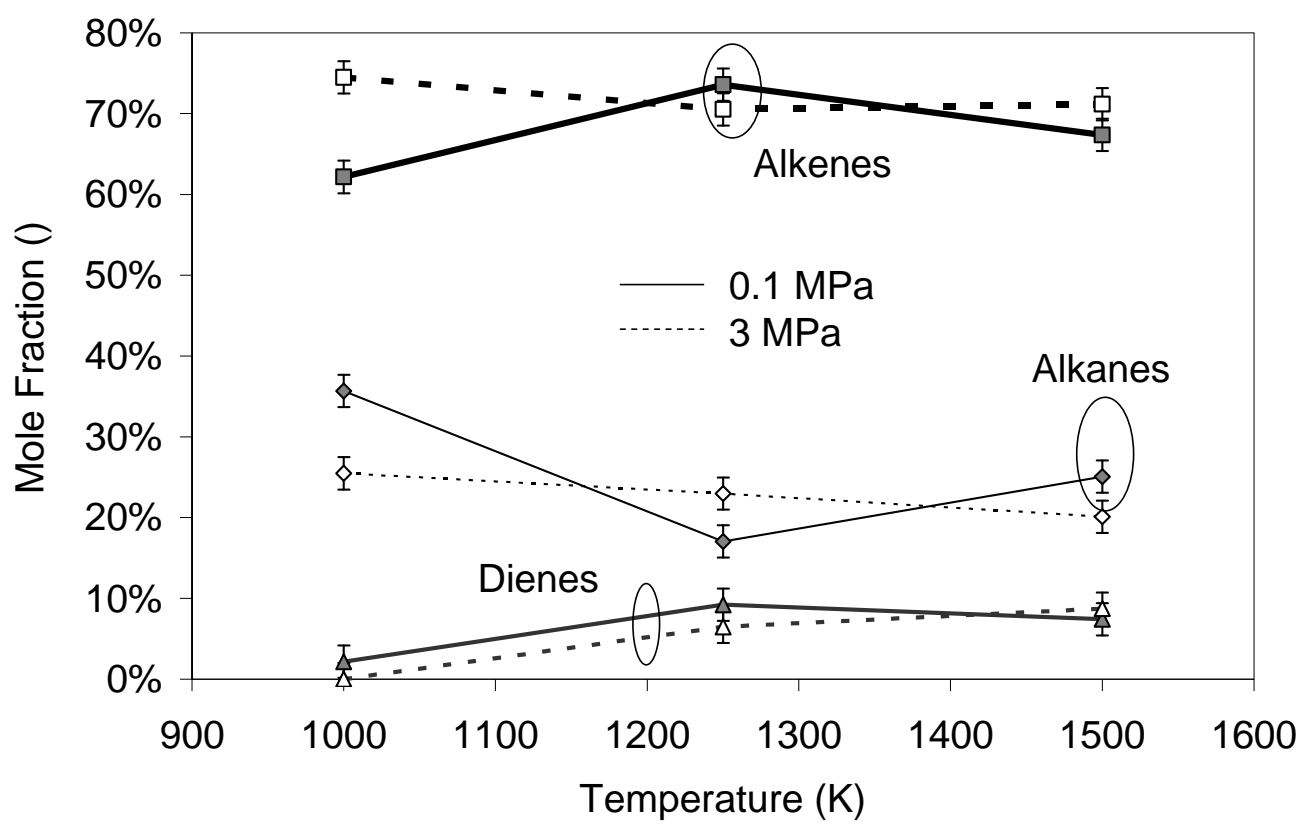

Figure 6. Formation of alkenes, alkanes and dienes at two pressure levels. 


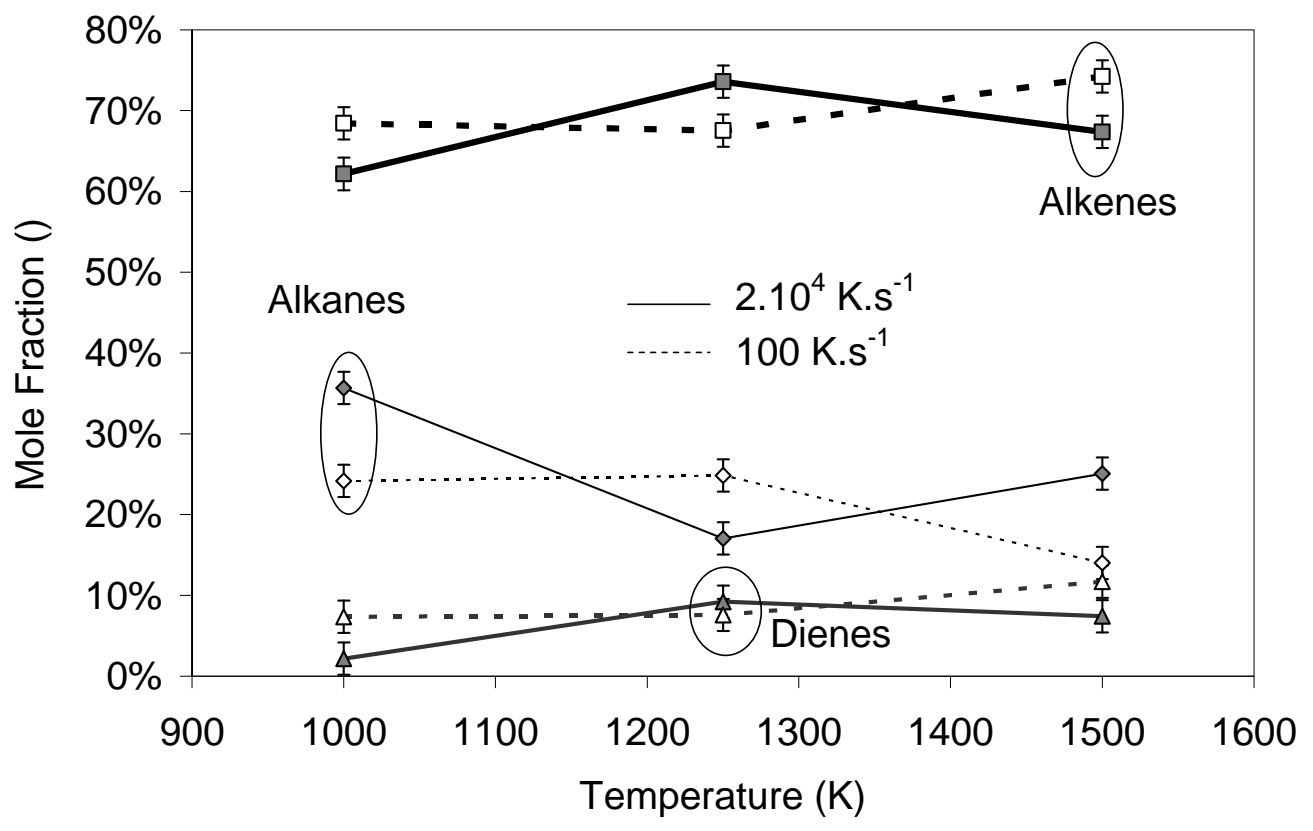

Figure 7. Formation of alkenes, alkanes and dienes at two heating rates. 